Editorial

\title{
Formation of ag/agcl nanoparticles
}

Volume 5 Issue 2 - 2017

\section{Editorial}

This is with reference to the article "Yeast- derived biosynthesis of silver/silver chloride nanoparticles and their anti proliferative activity against bacteria" RSC Advances Mateus Eugenio, Nathalia Müller, Susana Frasés, Rodrigo Almeida-Paes, Luís Maurício T. R. Lima, Leandro Lemgruber, Marcos Farina, Wanderley de Souza and Celso Sant'Anna; 2016, 6, 9893-9904, about the synthesis and some abntibacterial properties of $\mathrm{Ag}$ and $\mathrm{Ag} / \mathrm{AgCl}$ nanoparticles (NPs) formed from 15 clonal yeast isolated from termite gut.

The authors isolated yeast from the gut of 10 termites (TERM) from the species Cornitermes cumulans. The isolates were grown in culture medium containing $\mathrm{AgNO}_{3}$. A colour change from pale yellow to brown was ascribed to the formation of AgNP after 7 days in seven isolates (Table 1). A similar change in colour was also observed when $\mathrm{AgNO}_{3}$ and the supernatant of dead cell culture of isolates were incubated at $30^{\circ} \mathrm{C}$. surprisingly, it has also been ascribed to the formation of $\mathrm{Ag} / \mathrm{AgCl} \mathrm{NPs}$ (Figures $1 \mathrm{~A} \& \mathrm{1C}$ ). Authors have suggested that it was due to extracellular formation of $\mathrm{Ag} / \mathrm{AgCl} \mathrm{NPs}$. When extracellular and intracellular or dead and live bacterial cell culture yield the same result there does not seem to be any valid reason to believe that $\mathrm{AgCl}$ was also formed along with $\mathrm{AgNPs}$. $\mathrm{AgCl}$ NPs can be formed only if there is any species that furnishes $\mathrm{Cl}^{-}$ions in solution. And there is no addition of any chloride salt which may precipitate $\mathrm{Ag}^{+}$ions as $\mathrm{AgCl} \mathrm{NP}$ according to the following reaction.

$$
\mathrm{AgNO}_{3}+\mathrm{NaCl} \rightarrow \mathrm{AgCl}+\mathrm{NaNO}_{3}
$$

Table I Screening of yeast isolates capable of producing Ag/AgCl-NPs

\begin{tabular}{lll}
\hline Yeast Isolate & Medium Color Change & Uv-Vis Absorbance (AU) \\
\hline TERM73 (SNPPI) & Dark brown & 2.75 \\
TERM77 (SNPP2) & Dark brown & 3.13 \\
TERM78 & Light brown & 1.68 \\
TERM79 & Light brown & 1.9 \\
TERM82 & Light brown & 1.74 \\
TERM83 & Light brown & 1.89 \\
TERM89 & Light brown & 1.77 \\
\hline
\end{tabular}

The authors of this paper have shown that formation of $\mathrm{Ag} / \mathrm{AgCl}$ NPs by yeast isolates grown in the presence of $\mathrm{AgNO}_{3}$ was confirmed by an absorption in 350-450nm range in the UV-vis spectrum (Figures $1 \mathrm{~B} \& 1 \mathrm{D})$. This is attributed to the excitation of surface plasmaon resonance in $\mathrm{Ag}$ NPs. However, it may not be due to $\mathrm{AgCl}$ resonance because the presence of $\mathrm{AgCl}$ is dubious. The change in colour cannot be taken as an evidence for the formation of $\mathrm{AgCl} \mathrm{NP}$ because the absorbance observed at 410 and $415 \mathrm{~nm}$ are due to $\mathrm{Ag}$ NPs. ${ }^{1,2}$ Generally, the absorption peaks noted in 400-465nm in UV-vis spectra have been attributed to the formation of AgNP in solutions. ${ }^{3,4}$ If the $\mathrm{AgCl}$ is formed even in traces, it would settle at the bottom of the container and slowly turn grey due to its exposure to sun light but not brown as has been observed by authors. However, $\mathrm{AgCl}$ is solid and its solubility in water is negligible because its solubility product is too low to furnish $\mathrm{AgCl}$ ions.

\author{
KS Siddiqi,' Rahman A, ${ }^{2}$ Tajuddin ${ }^{2}$ \\ 'Department of Chemistry, Aligarh Muslim University, India \\ ${ }^{2}$ Department of Saidla, Aligarh Muslim University, India
}

Correspondence: Rahman A, Department of Saidla (Unani Pharmacy), Aligarh Muslim University, Aligarh-20200I, India Email rahman.mid@gmail.com

Received: February 23, 2017| Published: March 03, 2017

\section{$\mathrm{KspAgCl}=1.77 \times 10-10$ (At room temperature)}

The presence of $\mathrm{AgCl}$ would have been confirmed by the addition of ammonia which dissolves $\mathrm{AgCl}$ to give a clear solution. It can be reconfirmed by the addition of nitric acid to the above solution which gives white precipitate of $\mathrm{AgCl}$ again, as shown below.

$$
\mathrm{AgCl}+2 \mathrm{NH}_{4} \mathrm{OH} \rightarrow \mathrm{Ag}\left(\mathrm{NH}_{3}\right)_{2} \mathrm{Cl}+2 \mathrm{H} 2 \mathrm{O}
$$

(Solid)

(Soluble)

$$
\begin{gathered}
\mathrm{Ag}\left(\mathrm{NH}_{3}\right)_{2} \mathrm{Cl}+2 \mathrm{HNO}_{3} \\
(\text { Soluble })
\end{gathered} \rightarrow \underset{\text { (Solid) }}{\mathrm{AgCl}}+\underset{\mathrm{NH}_{4} \mathrm{NO}_{3}}{ }
$$
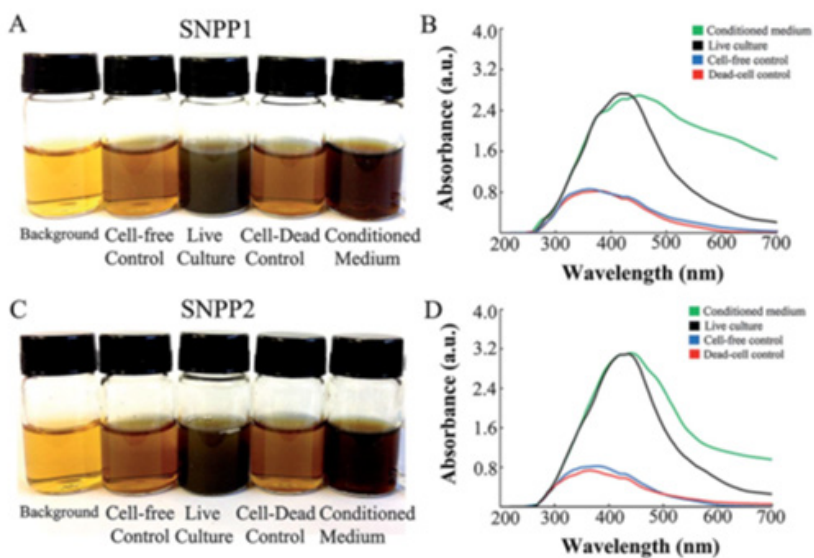

Figure I $N=57$; Epidemiological distribution of the pathological fractures, traumatic fractures, and nonunion.

These confirmatory tests were not done to verify the presence of $\mathrm{AgCl} \mathrm{NPs} \mathrm{nevertheless} \mathrm{the} \mathrm{authors} \mathrm{are} \mathrm{banking} \mathrm{solely} \mathrm{on} \mathrm{the} \mathrm{colour}$ 
change which may only be due to the presence of silver NP. The authors have suggested that the absorption peaks appearing at 434 and 435 from NPs produced from two termites (TERM 73, 77) and $\mathrm{AgNO}_{3}$ are due to $\mathrm{Ag} / \mathrm{AgCl} \mathrm{NPs}$. Further, heat killed yeast suspension containing same termites (TERM 73, 77) having dead strains of Candida lusitaniae and $\mathrm{AgNO}_{3}$ showed absorptions at 349 and 355 $\mathrm{nm}$ respectively. It has been suggested that reduction of $\mathrm{Ag} / \mathrm{AgCl}$ NPs occurred which exhibited the above absorption peaks. It is still not clear as to what was the source of chloride ion that resulted in the formation of $\mathrm{AgCl}$. Presence of chlorine has been inferred from SEM and EDS images which showed peaks for it. At this stage the presence of $\mathrm{Cl}$ cannot be denied but the source is unclear.

We have tested commercially available yeast for chloride ion. The supernatant of yeast solution in distilled water was incubated with $1 \mathrm{mM}$ solution of $\mathrm{AgNO}_{3}$ at room temperature (i) and (ii) also after heating at $70^{\circ} \mathrm{C}$ in two different sets. The precipitate was formed and a change in colour occurred but it did not dissolve in $\mathrm{NH}_{3}$. This precipitate may have been formed due to the formation of silver hydroxide but it is not $\mathrm{AgCl}$ because it did not dissolve in ammonia.

None of the references..$^{5-7}$ cited by the authors of the above paper at serial number $1,12,13$ are related to $\mathrm{Ag} / \mathrm{AgCl}$ formation. They are not relevant and give only the formation of silver NPs. The formation of $\mathrm{Ag} / \mathrm{AgCl}-\mathrm{NP}$ from $\mathrm{AgNO}_{3}$ in absence of chloride ions is highly improbable.

\section{Acknowldgments}

None.

\section{Conflicts of interest}

None.

\section{References}

1. Zaheer Z, Rafiuddin Silver nanoparticles to self assembled films: Green synthesis and characterization. Colloids Surf B: Biointerfaces. 2012;90:48-52.

2. Nguyen TMT, Tran NMA, Mai DT et al. Green Synthesis of Silver Nanoparticles Using Nelumbo nucifera Seed Extract and its Antibacterial Activity. Acta Chim Slov. 2013;60(3):673-678.

3. Gliga AR, Skoglund S, Wallinder IO et al. Size-dependent cytotoxicity of silver nanoparticles in human lung cells: the role of cellular uptake, agglomeration and Ag release. Part Fibre Toxicol. 2014;11:11.

4. Geethalakshmi R, Sarada DVL Characterization and antimicrobial activity of gold and silver nanoparticles synthesized using saponin isolated from Trianthema decandra L. Industrial Crops and Products. 2013;51:107-115.

5. Naveen KSH, Kumar G, Karthik L, Rao KVB Extracellular biosynthesis of silver nanoparticles using the filamentous fungus Penicillium sp. Arch Appl Sci Res. 2010;2:161-167.

6. Mafuné F, Kohno J, Takeda Y et al. Structure and Stability of Silver Nanoparticles in Aqueous Solution Produced by Laser Ablation. $J$ Phys Chem B. 2000;104(35):8333-8337.

7. Hyning DLV, Zukoski CF Formation Mechanisms and Aggregation Behavior of Borohydride Reduced Silver Particles. Langmuir. 1998;14(24):7034-7046. 